\title{
Distribution and developmentally regulated expression of murine polycystin
}

\author{
LIN GENG, ${ }^{1}$ YOAV SEGAL, ${ }^{1}$ ANNA PAVLOVA, ${ }^{1}$ ELVINO J. G. BARROS,${ }^{1}$ \\ CORINNA LÖHNING, ${ }^{2}$ WEINING LU, ${ }^{1}$ SANJAY K. NIGAM, ${ }^{1}$ \\ ANNA-MARIA FRISCHAUF, ${ }^{2}$ STEPHEN T. REEDERS, ${ }^{1}$ AND JING ZHOU1 \\ ${ }^{1}$ Renal Division, Brigham and Women's Hospital, Harvard Medical School, \\ Boston, Massachusetts 02115; and 2 Imperial Cancer Research Fund, \\ London WC2A 3PX, United Kingdom
}

Geng, Lin, Yoav Segal, Anna Pavlova, Elvino J. G. Barros, Corinna Löhning, Weining Lu, Sanjay $K$. Nigam, Anna-Maria Frischauf, Stephen T. Reeders, and Jing Zhou. Distribution and developmentally regulated expression of murine polycystin. Am. J. Physiol. 272 (Renal Physiol. 41): F451-F459, 1997.-PKD1, the gene that is mutated in $-85 \%$ of autosomal dominant polycystic kidney disease (ADPKD) cases in humans, has recently been identified (Eur. PKD Consortium. Cell 77: 881-894, 1994; also, erratum in Cell 78: 1994). The longest open-reading frame of PKD1 encodes polycystin, a novel $\sim 460-\mathrm{kDa}$ protein that contains a series of $\mathrm{NH}_{2}$-terminal adhesive domains ( $\mathrm{J}$. Hughes, C. J. Ward, B. Peral, R. Aspinwall, K. Clark, J. San Millan, V. Gamble, and P. C. Harris. Nat. Genet. 10: 151-160, 1995; and Int. PKD Consortium. Cell 81: 289-298, 1995) and several putative transmembrane segments. To extend studies of polycystin to an experimentally accessible animal, we have isolated a cDNA clone encoding the $3^{\prime}$ end of Pkd1, the mouse homologue of PKD1, and raised a specific antibody to recombinant murine polycystin. This antibody was used to determine the subcellular localization and tissue distribution of the protein by Western analysis and immunocytochemistry. In the mouse, polycystin is an $\sim 400-\mathrm{kDa}$ molecule that is predominantly found in membrane fractions of tissue and cell extracts. It is expressed in many tissues including kidney, liver, pancreas, heart, intestine, lung, and brain. Renal expression, which is confined to tubular epithelia, is highest in late fetal and early neonatal life and drops 20 -fold by the third postnatal week, maintaining this level into adulthood. Thus the temporal profile of polycystin expression coincides with kidney tubule differentiation and maturation.

PKD1; polycystic kidney disease; kidney development; immunohistochemistry; Western analysis

RENAL EPITHELIAL CYST formation is the central pathophysiological feature in a host of congenital and acquired human diseases. Among these, autosomal dominant polycystic kidney disease (ADPKD) is the most common, affecting over 500,000 individuals in the United States. Viewed as a prototype, ADPKD is characterized by progressive focal dilatation of scattered tubular nephron segments, resulting in cystic replacement of normal renal parenchyma, and irreversible renal failure during adult life (7). Cysts can also be found in the liver and pancreas. Cyst formation has been associated with abnormal proliferative capacity of epithelial cells, loss of polarized epithelial phenotype, fluid accumulation resulting from abnormal secretion, and changes in extracellular matrix composition $(2,10$, 18). Despite information emerging about the mutated gene products in this disorder (see below), the precise nature of the primary defects and the mechanisms that lead to cyst formation remain poorly understood. Likewise, although a large number of hereditary cystic diseases have been studied in rodents $(8,14,20,29,30)$, the mutated gene has only been identified in one model (20), and study of these animals has not yet provided broad insights into the pathogenesis of renal cysts.

Mutations in at least three genetically distinct genes cause ADPKD. The PKD1 and PKD2 genes are located on chromosomes $16(28)$ and 4 , respectively $(6,17)$. The third locus has not been mapped (3). PKD1, which accounts for over $85 \%$ of ADPKD cases (7), has recently been identified (5). The longest open-reading frame encodes polycystin, an $\sim 4,300$-residue protein whose $\mathrm{NH}_{2}$ terminus contains a signal peptide and a series of adhesive domains including two leucine-rich repeats, a C-type lectin domain, a low-density lipoprotein-A domain, and at least 13 tandem copies of a novel "PKD" domain $(13,15)$. At the $\mathrm{COOH}$ terminus, there is a hydrophobic region containing 9-11 putative membrane-spanning segments and an intracellular segment of $\sim 200$ residues $(13,15)$. More than a dozen mutations have been identified in PKD1, including deletions $(5,25)$ and nonsense (32) and missense mutations (26). PKD2, which accounts for $\sim 10 \%$ of $\mathrm{ADPKD}$ cases, encodes a 968-residue protein containing six putative membrane-spanning segments with intracellular $\mathrm{NH}_{2}$ and $\mathrm{COOH}$ termini (19). There is $-25 \%$ identity and $\sim 50 \%$ similarity between the PKD2 protein and a 450-amino acid stretch from the hydrophobic region of polycystin. The PKD2 protein shares homology with voltage-activated $\mathrm{Ca}^{2+}$ and $\mathrm{Na}^{+}$channels (19). The functions of PKD1 and PKD2 are not known.

Recent studies have shown that human polycystin is expressed in fetal and adult kidneys $(9,11,34)$ and in a range of other tissues $(9,11)$. The level of polycystin is higher in fetal than in adult life (9). However, detailed study of the developmental regulation of this protein in humans is limited by the availability of staged tissues.

To learn how the structural features of polycystin contribute to its function and to obtain information on the effects of interactions with its ligand(s), it will be valuable to study an experimentally accessible animal, such as the mouse, in which genetic and surgical manipulations are possible and in which a wide range of tissues are available. Although naturally occurring mutations of the mouse homologue of PKD1 have not been observed, these studies will also lay the groundwork for the study of polycystin in the large range of 
genetic, transgenic, and drug-induced models of polycystic kidney disease in the mouse $(8,14,16,30,31)$. Comparisons of the localization and regulation of polycystin in humans and mice are also necessary to validate the use of targeted mouse mutants as models of the human disease.

Here we have isolated a partial murine homologue of PKD1, Pkd1, and raised a specific antibody to the recombinant protein. Sequence, biochemical, and immunohistochemical evidence is provided to demonstrate that murine polycystin is very similar to human polycystin. A detailed analysis by Northern and Western blotting shows that polycystin expression appears late in kidney development and drops dramatically during postnatal development, coincident with the final stages of nephron maturation.

\section{MATERIALS AND METHODS}

Production of fusion proteins and antisera. A fusion protein, mpkcr, was generated by expressing a portion of Pkd1 cDNA clone MC82 containing the putative intracellular domain at the extreme $\mathrm{COOH}$ terminus of murine polycystin (homologous to PKD1 cDNA sequence, nucleotides 1247813137) $(13,15)$ in the pMAL-C2 expression vector (New England Biolabs, Beverly, MA). Two rabbits were immunized with $0.1 \mathrm{mg}$ of fusion protein. For affinity purification, antibodies were first passed through a maltose binding protein (MBP)-coupled column to eliminate antibodies against MBP and then affinity purified using membrane-bound fusion proteins. Briefly, fusion proteins were electrophoresed on a $10 \%$ sodium dodecyl sulfate-polyacrylamide gel electrophoresis (SDS-PAGE) gel and electrotransferred onto polyvinylidene difluoride (PVDF) Immobilon membranes (Millipore, Bedford, MA). Antisera were incubated with the membrane overnight and washed with washing buffer $[500 \mathrm{mM} \mathrm{NaCl}, 10$ $\mathrm{mM}$ tris(hydroxymethyl)aminomethane (Tris) hydrochloride, $\mathrm{pH} 7.5$, and $0.2 \%$ Triton X-100] three times at room temperature. The bound antibodies were eluted in $0.1 \mathrm{M}$ glycine- $\mathrm{HCl}$, $\mathrm{pH}$ 3.2. The reactivity of the affinity-purified antibodies was demonstrated by blotting with fusion protein.

Northern analysis. Time-mated pregnant micc (day 10) were purchased from Taconic (Germantown, NY) or Charles River Laboratories (Cambridge, MA). Individual embryos were dissected free of surrounding tissue under direct vision using a binocular dissecting microscope as described (36). Earliest dissectable kidneys were from days 11.5-12 embryos $(E 11.5-E 12)$ in which nondivided ureteric buds could be identified. Total RNA was isolated from various stages of whole embryos or embryonic tissues and from adult mouse (3 mo old) as previously described (36). About $10 \mu \mathrm{g}$ of total RNA represent the yield from 10-20 early embryonic kidneys. The Northern blots were probed with a ${ }^{32}$ P-labeled mouse Pkd1 cDNA fragment homologous to the most 3' PKD1 cDNA coding sequence. $\mathrm{A}^{32} \mathrm{P}$-labeled cDNA fragment of glyceraldehyde-3-phosphate dehydrogenase was used as a control probe to demonstrate equal loading of RNA in each lane.

Membrane isolation from mouse tissues. Individual mouse embryos were dissected as described above. Various organs were homogenized in buffer $[10 \mathrm{mM}$ phosphate buffer, $20 \mathrm{mM}$ $\mathrm{KCl}, 5 \%$ sucrose, $0.5 \mathrm{mM} \mathrm{MgCl} 2,1 \mathrm{mM}$ EDTA, $1 \mathrm{mM}$ ethylene glycol-bis( $\beta$-aminoethyl ether)- $N, N, N^{\prime}, N^{\prime}$-tetraacetic acid (EGTA), $1 \mathrm{mM}$ dithiothreitol (DTT), $1 \mathrm{mM}$ phenylmethylsulfonyl fluoride (PMSF), $5 \mu \mathrm{g} / \mathrm{ml}$ pepstatin A, $5 \mu \mathrm{g} / \mathrm{ml}$ antipain, and $2.5 \mathrm{\mu g} / \mathrm{ml}$ leupeptin]. Tissue homogenates were centrifuged successively at $1,000 \mathrm{~g}$ for $15 \mathrm{~min}, 8,000 \mathrm{~g}$ for $20 \mathrm{~min}$, and $100,000 \mathrm{~g}$ for $2 \mathrm{~h}$. Supernatant $(S 100)$ and pellet fractions (P8, pellet of $8,000 \mathrm{~g}$; and $P 100$, pellet of $100,000 \mathrm{~g}$ ) were collected. Pellets were resuspended in the homogenization buffer, snap frozen in liquid nitrogen, and stored at $-80^{\circ} \mathrm{C}$. All steps were performed at $4^{\circ} \mathrm{C}$. Protein concentrations were measured by the Bradford method.

Cell culture and preparation of inner medullary collecting duct cell membranes. Inner medullary collecting duct (IMCD) cells (27) were grown to confluence in Dulbecco's modified Eagle's medium + Ham's F-12 with $10 \%$ fetal calf serum. The cells were washed three times in phosphate-buffered saline (PBS), scraped, and homogenized in buffer (5\% sucrose, 20 $\mathrm{mM}$ Tris $\cdot \mathrm{HCl}, 1 \mathrm{mM}$ EDTA, $1 \mathrm{mM}$ EGTA, $1 \mathrm{mM}$ DTT, $1 \mathrm{mM}$ PMSF, $5 \mu \mathrm{g} / \mathrm{ml}$ pepstatin A, $5 \mu \mathrm{g} / \mathrm{ml}$ antipain, and $2.5 \mu \mathrm{g} / \mathrm{ml}$ leupeptin). Membrane fractions were isolated as described above.

Western blotting. Protein samples (5-10 $\mu \mathrm{g}$ of fusion proteins or $100-200 \mu \mathrm{g}$ of tissue fractions) were solubilized in sample buffer [ $2 \%$ SDS, $30 \mathrm{mM}$ Tris $\cdot \mathrm{HCl}, \mathrm{pH} 6.8,5 \%$-mercaptoethanol, and $12 \%(\mathrm{vol} / \mathrm{vol})$ glycerol] and electrophoretically fractionated on 5-10\% SDS-PAGE nongradient gels after boiling. Proteins were electrotransferred to PVDF Immobilon membranes and blotted with specific antibodies (mpkcr-Ab at 1:1,000 dilution, purified antisera at 1:10) in blotting buffer ( $5 \%$ nonfat dry milk in $0.15 \mathrm{M} \mathrm{NaCl}, 1 \%$ Triton $\mathrm{X}-100$, and $20 \mathrm{mM}$ Tris $\cdot \mathrm{HCl}, \mathrm{pH}$ 7.4). After several washes, the membranes were incubated with peroxidase-conjugated secondary antibody and detected by enhanced chemiluminescence (ECL, Amersham).

Immunocytochemistry. Immunocytochemistry was carried out as previously described (24). Tissues embedded in OCT optimal cutting temperature compound (Miles, Elkhart, IN) were cross sectioned at $5 \mu \mathrm{m}$ in a cryostat at $-20^{\circ} \mathrm{C}$. Sections were air dried for $30 \mathrm{~min}$ and then fixed in acetone for $5 \mathrm{~min}$. After brief air drying, sections were rinsed three times in PBS and incubated with $20 \mu \mathrm{l}$ of primary antibody for $1 \mathrm{~h}$. Mpkcr-Ab antisera were used at a dilution of 1:100. Control sections were incubated with preimmune serum at the same concentration. For antigen-blocking experiments, antibodies were preincubated with a specific antigen (either in solution or on an immunoblot) for $1 \mathrm{~h}$ at room temperature. After washing, the sections were incubated for 45 min with $20 \mu l$ of fluorescein isothiocyanate-conjugated goat anti-rabbit immunoglobulin G (IgG; Sigma Chemical, St. Louis, MO) for 30 min at room temperature, mounted in glycerol and PBS, and observed with epifluorescent illumination.

Immunoperoxidase staining was carried out using the Vectastain Elite ABC kit (Vector, Burlingame, CA) containing avidin and biotinylated horseradish peroxidase. Primary polyclonal antibodies were diluted to 1:500. Biotinylated goat anti-rabbit IgG (Vector) were used as secondary antibodies. Diaminobenzidine tetrahydrochloride was used as a chromogen, and methyl green or hematoxylin was used for counterstaining (Sigma). Photographs were taken with a Nikon 200 and Kodak 25 ISO color film.

\section{RESULTS}

The mouse homologue of polycystin. A mouse fetal kidney cDNA library was screened with human PKD1 cDNA clones (Löhning et al., unpublished observations). One of the mouse clones, MC82, hybridized to the 3 ' end of PKD1 and contained an open-reading frame that encodes a peptide with $77 \%$ sequence identity and $84 \%$ sequence similarity to the $\mathrm{COOH}$ terminus of human polycystin $(13,15)$ (Fig. 1). The mouse 
Mouse

1 LLCVGLWALRVWGALRLGAILLRWRYHALRGELYRPAWEPQDYEMVELFL 50 ||||||||||: |||||||||: :||||||||||||||||||||||||||||||

Human 4084 LLCVGLWALRLWGALRLGAVILRWRYHALRGELYRPAWEPQDYEMVELFL 413

51 RRLRLWMGFSKVKEFRHKVRFEGMDPLPSRSSRGSKSSPVVLPPSSGSEA 100 ||||||||$:||||||||||||||:|||||||||||||||||\cdot||:|$

4134 RRLRLWMGLSKVKEFRHKVRFEGMEPLPSRSSRGSKVSPDVPPPSAGSDA 4183

101 SHPSTSSSQPDGPSASLSRSTLKLEPEPSRLHAVFESLLVQFDRLNQATE 150

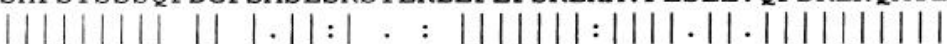

4184 SHPSTSSSQLDGLSVSLGRLGTRCEPEPSRLQAVFEALLTQFDRLNQATE 4233

151 DVYQLEQQLQSLRGHGHNGPPSSPSPGCFPGSQPALPSRLSRASQGLDQT 200 ||||||||$:|| \cdot|: \quad .:| .: .|\cdot| .|| .|||||| \cdot|||\cdot|: \mid$.

4234 DVYQLEQQLHSLQGRRSSRAPAGSSRGPSPGLRPALPSRLARASRGVDLA 4283

201 VGPNRVSLWPNNKVHPSST 219

$.|| .|\ldots|:: .||||||||$

4284 TGPSRTPLRAKNKVHPSST 4302
Fig. 1. Comparison of $\mathrm{COOH}$-terminal peptide sequences of the murine and human polycystin. Top line: deduced amino acid sequence of a portion of murine polycystin used to raise antibody mpkcr-Ab. Bottom line: corresponding human sequence (15). Numbering of the human sequence is according to the International PKD Consortium (15). Residues that are identical in both species are indicated by vertical lines $(\mid)$; residues that are similar in both species are indicated by $\operatorname{dots}($ or :) gene, designated $\mathrm{Pkd} 1$, is not homologous to $\mathrm{PKD} 2$ or any other known sequences except PKD1.

Polycystin antibodies. Polyclonal antisera (mpkcr$\mathrm{Ab}$ ) were raised against mpkcr, a polycystin-MBP recombinant protein containing the most $\mathrm{COOH}$-terminal 219 residues of murine polycystin (MATERIALS AND METHoDs, Fig. 1). Following cleavage of the fusion protein, mpkcr-Ab reacted strongly with mpkcr (data not shown). Mpkcr-Ab detected an $\sim 400-\mathrm{kDa}$ band on immunoblots of mouse embryonic kidney tissue. This protein is indistinguishable in size from the protein detected in human tissue extracts by two anti-human polycystin antibodies (9). The reactivity of mpkcr-Ab with the $400-\mathrm{kDa}$ protein was blocked by preadsorption with mpkcr but not with MBP alone, demonstrating that immunoreactivity is specific to polycystin (Fig. 2). Preimmune serum did not react with mouse embryonic kidney tissue extracts (Fig. 2). Trace reactivity of mpkcr-Ab with 200 - and $70-\mathrm{kDa}$ bands was observed, although the $200-\mathrm{kDa}$ band can scarcely be seen on photographic reproductions. The intensity of these bands varied greatly between experiments. Reactivity of mpkcr-Ab with the $200-\mathrm{kDa}$ band was blocked by mpkcr (Fig. 2). These data suggest that the $200-\mathrm{kDa}$ protein is likely to be a proteolytic product of full-length polycystin.

The Pkd1 transcript. Northern analysis was carried out to evaluate the size of the predominant Pkd1 transcript and to investigate the possibility of splice variants accounting for the $200-$ and $70-\mathrm{kDa}$ bands. Using the MC82 probe to study embryonic day 18 (E18) and adult mouse kidneys as well as various stages of whole embryos, we detected a single band of $\sim 14 \mathrm{~kb}$, even after prolonged autoradiography (Fig. 3). The Pkd1 transcript was first detected in total mouse embryos at day 10.5, the earliest stage we examined. We could not detect any signal in $E 18$ or adult livers on three separate Northern blots (Fig. 3), indicating that the level of Pkd1 mRNA in liver is much lower than that in kidneys in mice of the same age. The absence of multiple bands on the Northern blots suggests that alternatively spliced transcripts containing the extreme 3 ' end of Pkd1 are not abundant, at least in the stages and tissues we examined. The Pkd1 transcript is similar in size to the human PKD1 mRNA.

Murine polycystin is membrane-associated and expressed in many tissues. By both reverse transcriptionpolymerase chain reaction and Western analyses it was found that IMCD cells, derived from mouse IMCDs, expressed polycystin at high levels. These cells are able to form polarized monolayers and tubular structures in vitro. IMCD cells might therefore provide a model system for the exploration of the role of polycystin in cell differentiation and tubulogenesis and were therefore used to determine the subcellular localization of the protein (Fig. 4A). Polycystin was found in mem.

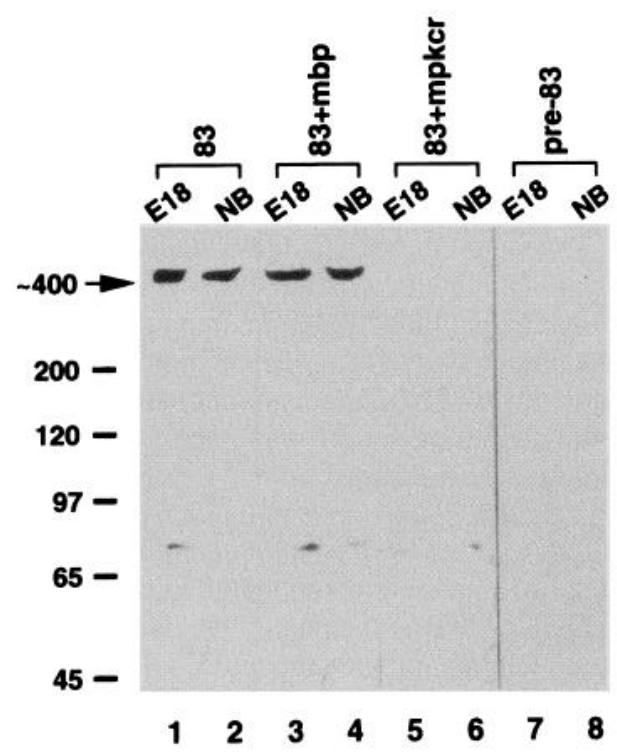

Fig. 2. Characterization of an anti-murine polycystin antibody. Embryonic day 18 (E18) and newborn (NB) mouse kidney tissues ( 200 $\mu \mathrm{g}$ of $P 100$ fraction) were blotted with rabbit anti-mouse polyclonal antibody mpkcr-Ab (83, lanes 1 and 2$)$; with mpkcr-Ab that had been preadsorbed with maltose binding protein (MBP) $(83+\mathrm{mbp}$, lanes 3 and 4); with mpkcr-Ab that had been preadsorbed with its immunogen, mpkcr $(83+$ mpkcr, lanes 5 and 6$)$; and with preimmune sera (pre-83, lanes 7 and 8). Molecular mass markers are indicated on left. Mpkcr-Ab detects a protein of $\sim 400 \mathrm{kDa}$ (arrow). Reactivity of mpkcr-Ab with the $400-\mathrm{kDa}$ protein was blocked by mpckr, a specific antigen, but not by MBP. 


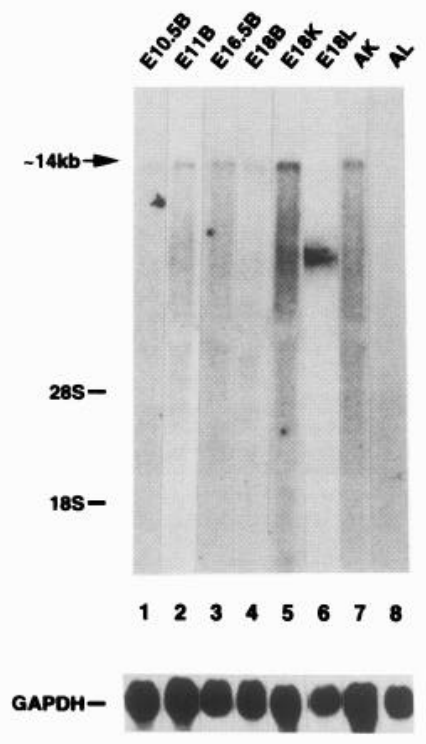

Fig. 3. Pkd1 encodes an $\sim 14$-kb transcript. Northern analysis of Pkd1 in whole mouse embryos (lanes 1-4) and embryonic and adult kidneys and liver (lanes 5-8). E, embryonic; A, adult (8 wk of age); B, total body; K, kidney; $\mathrm{L}$, liver. Total RNAs $(\sim 30 \mu \mathrm{g})$ were separated on a $30-\mathrm{cm} 0.8 \%$ agarose gel and hybridized with a ${ }^{32} \mathrm{P}$-labeled $\mathrm{Pkd} 1$ cDNA probe (MATERIAL AND METHODS). Only a single band of $\sim 14 \mathrm{~kb}$ was detected even after prolonged autoradiography (arrow). Pkd1 transcript is present but at a lower level in adult kidneys. Glyceraldehyde-3-phosphate dehydrogenase (GAPDH) was used as a loading control (bottom).

brane fractions but not in cytosolic fractions of IMCD cells (Fig. 4A). It was also found in $P 100$ membrane fractions of tissue extracts from kidney (Figs. 2 and $4 B$ ) and other organs including heart, brain, liver, lung, pancreas, and small intestine (Fig. $4 B$ ). These findings suggest that murine polycystin is either an integral membrane protein, as has been proposed for human polycystin based on the deduced protein sequence (13), or is a protein that is closely associated with the cell plasma membrane or with intracellular membranes or organelles.

Developmental regulation of polycystin expression. To determine the developmental profile of murine polycystin expression, fetal and neonatal kidneys from E12 to birth were studied by Northern analysis. A Pkd1 transcript was first identified at E14 when nephrogenic induction is still a major event in kidney development, but the greatest expression was observed between $E 16$ and $E 19$ when nephrogenic induction is complete. In the adult mouse, transcript levels were significantly lower than in late fetal life (Figs. 3 and 5).

Western analysis was carried out in mouse embryos from $E 10.5-E 17.5$ and in kidneys from $E 14$ to adulthood. Polycystin levels are highest in mouse embryos on $E 10.5$ and decrease thereafter (Fig. 6). In the kidney, a high level of expression was detected on E14 through 1 wk after birth (Fig. 6). Between the first and the second postnatal weeks the level of expression drops by at least sixfold (Fig. 6). With prolonged exposure of autoradiographs, a very faint band ( $>20$-fold weaker) was detected in mice older than $3 \mathrm{wk}$ into adulthood, indicating that a very low level of murine polycystin expression is maintained throughout life. The intensity of the 70-kDa protein decreases in a similar manner. At 1 wk after birth, a new $45-\mathrm{kDa}$ band appears and increases in intensity as polycystin expression decreases. The nature of this $45-\mathrm{kDa}$ band requires further investigation. Two mouse strains (CD1 and $\mathrm{BALB} / \mathrm{c}$ ) were compared; the temporal and spatial expression patterns were similar in both strains (data not shown).

Mouse polycystin expression is restricted to tubular epithelial cells in the kidney. To determine the spatial and temporal patterns of polycystin expression within the kidney, immunocytochemistry was performed on E10.5 through newborn, postnatal (from week 1 to 8 )

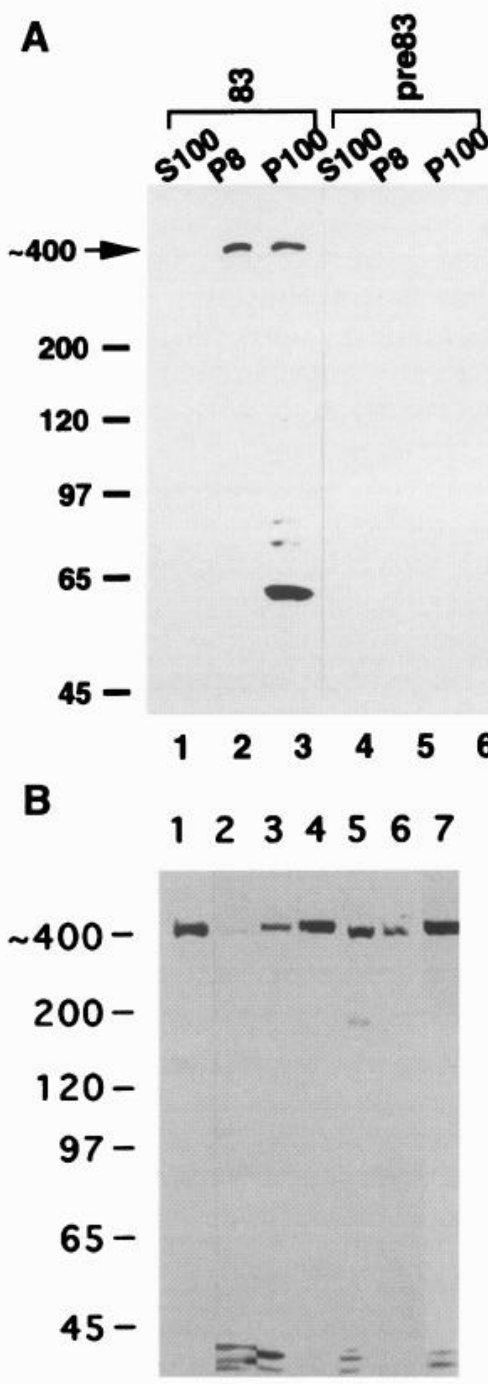

Fig. 4. Subcellular localization of murine polycystin. $A$ : subcellular localization of murine polycystin in inner medullary collecting duct (IMCD) cells. Fractions of IMCD cell lysate $(\sim 200 \mu \mathrm{g})$ were separated on a 5\% SDS-polyacrylamide gel electrophoresis gel, electrotransferred to a Nylon membrane, and blotted with mpkcr-Ab (83, lanes 1-3). Murine polycystin was found in P8 (lane 2) and P100 (lane 3) fractions but not in the $S 100$ (lane 1) fraction. Preimmune sera did not show any reactivity (lanes 4-6). Molecular mass markers are left. $B$ : polycystin expression in various mouse organs at day 3 after birth. P100 membrane fractions $(\sim 200 \mu \mathrm{g})$ of heart, brain, liver, lung, kidney, pancreas, and small intestine (lanes $1-7$, respectively) were immunoblotted with mpkcr-Ab. 


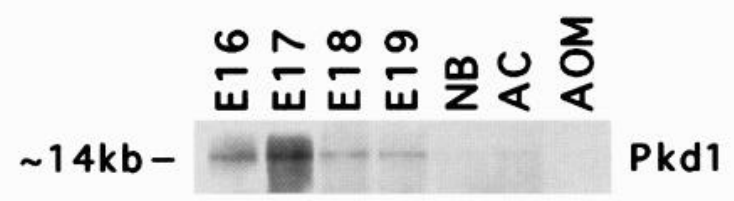

\section{$-\infty-0-\pi=$ GAPDH}

Fig. 5. Northern analysis of $\mathrm{Pkd} 1$ transcript in kidneys at different stages of development. Total RNAs $(\sim 10 \mu \mathrm{g})$ from embryonic mouse kidneys from day 12 to newborn and adult kidneys were analyzed by Northern analysis using a Pkd1 cDNA probe. Only E16 to adult are shown. Pkd1 expression increases to a peak between E16 and E19. The level of expression is lower in the adult mouse ( 3 mo old). NB, newborn; AC, adult cortex; AOM, adult outer medulla.

and adult mouse kidneys. Staining of E18, newborn, and adult kidneys by both immunofluorescence and immunoperoxidase methods gave identical results. No specific structures were clearly stained in kidneys earlier than $E 13.5$, although immunoperoxidase reactivity was clearly above background level. During the subsequent differentiation stages, staining became concentrated in the epithelial structures. In kidneys of $E 15.5$, polycystin was clearly detected in the ureteric bud, collecting tubules, and renal pelvis (Fig. 7, $A-E$ ). Staining was weakest in the tip of the bud, suggesting that polycystin does not have a major role in nephrogenic induction (Fig. 7A). No signals were detected in mesenchyme-derived structures at early (condensates, comma- and S-shaped bodies) (Fig. 7B) or late stages of differentiation (tubule elongation) of renal tubulogenesis (21). Polycystin was also absent from uninduced mesenchyme itself (Fig. 7A), differentiated stroma (Fig. $7 D$ ), and developing and mature glomeruli (Fig. 7, $B$ and $C$ ). In $E 18$ kidneys, high levels of expression were also observed in the collecting duct system, the papillae, and the renal pelvis (Fig. $7 F$ ), which are all derived from the ureter, and in the ureter itself (23). Within the collecting duct system, polycystin was found in both papillary ducts that are situated in the medulla of the kidney and in the straight collecting ducts of the kidney periphery. The level of expression in the papillae was slightly weaker than that in the collecting ducts in the outer medulla (Fig. $7 F$ ); this difference became more evident in the newborn kidney (Fig. $7 G$ ). No immunoreactivity was detected in endothelial or smooth muscle cells in renal vessels.

Levels and distribution of polycystin in kidneys from newborn (Fig. 7G) and 1-wk-old mice (Fig. 7, $H$ and $I$ ) were indistinguishable from those of E18 kidneys by immunostaining. After the first postnatal week, epithelial staining decreased gradually, and by postnatal day 21 , staining of the collecting system decreased to a very low level that was just above background levels. The low level of staining seen at day 21 was maintained through adulthood (Fig. $7 J$ ).

Polycystin expression in other organs. Polycystin expression was also investigated in other organs, including the liver, pancreas, heart, small intestine, brain, and spleen (Fig. 8). Polycystin was found in the hepatic bile ducts and pancreatic ducts (Fig. 8, $A$ and $B$ ). Weak staining in the acinar cells was noted. The protein was also found in villi of the small intestine, choroid plexus and ependyma in the brain, and bronchioles in the lung (Fig. 8, $C, E$, and $F$ ). Although in most organs expression was restricted to epithelia, a low level of expression was observed in the myocardium (Fig. 8D). Vascular endothelial cells were consistently negative. We did not detect polycystin in the spleen (data not shown).

\section{DISCUSSION}

Although polycystin, the product of the human PKD1 gene, contains several recognizable protein motifs, including $\mathrm{NH}_{2}$-terminal adhesive domains and several probable transmembrane domains, the overall structure of the molecule is unlike any known protein, precluding a provisional assignment of its function. Many of the most powerful approaches to understanding the function of polycystin and the pathophysiology of renal cystic diseases require the development of model systems in which the interactions of polycystin can be studied. The aims of this study were to demonstrate that the distribution of murine polycystin at the cellular and tissue levels is similar to that of the human protein and to better define the developmental profile of polycystin expression during fetal and neonatal life. We

\section{1}

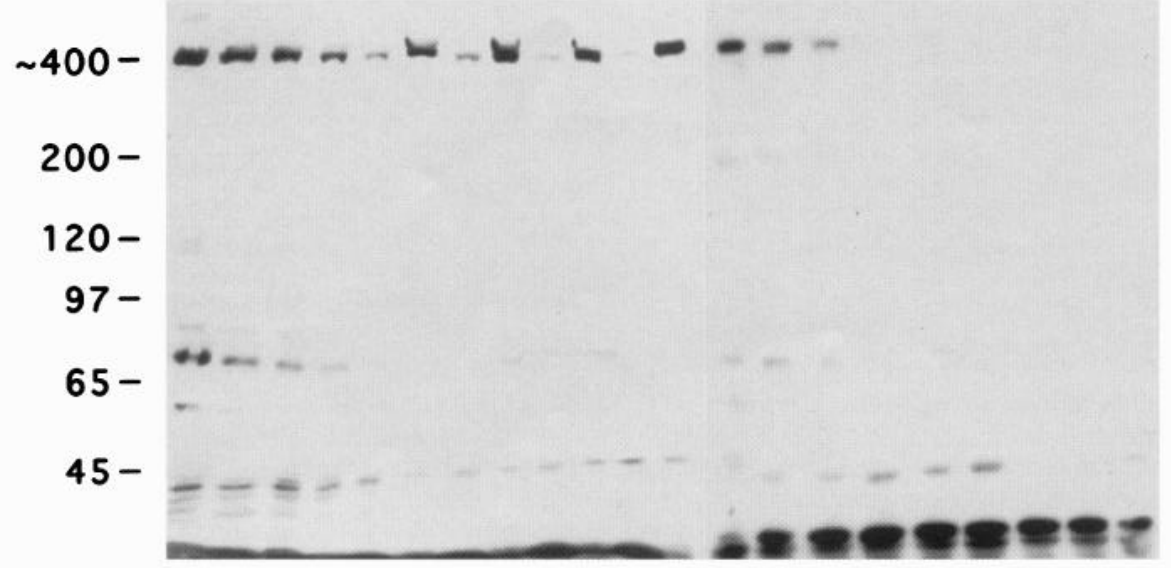

Fig. 6. Murine polycystin expression is developmentally regulated. Membrane fractions $(\sim 200$ $\mu \mathrm{g}$ ) of total embryos (lanes 1-5, 7, 9, 11) at different embryonic stages $(E 10.5, E 11.5, E 12.5$, $E 13.5, E 14.5, E 15.5, E 16.5$, and $E 17.5$, respectively) and kidney membrane fractions (lanes 6 , 8,10 , and 12-21) at different developmental stages (E14.5, E15.5, E16.5, E17.5, E18, 1-, 2-, 3-, 4-, 5-, 6-, 8-wk, and adult, respectively) were blotted with mpkcr-Ab. Polycystin expression starts to decrease in the total embryo on E13.5, whereas in the kidney it begins to decease at the second postnatal week. Expression in the kidney decreased to trace level by the third postnatal week. A faint band could be seen in mice older than $3 \mathrm{wk}$ and in adult mice with prolonged exposure. 

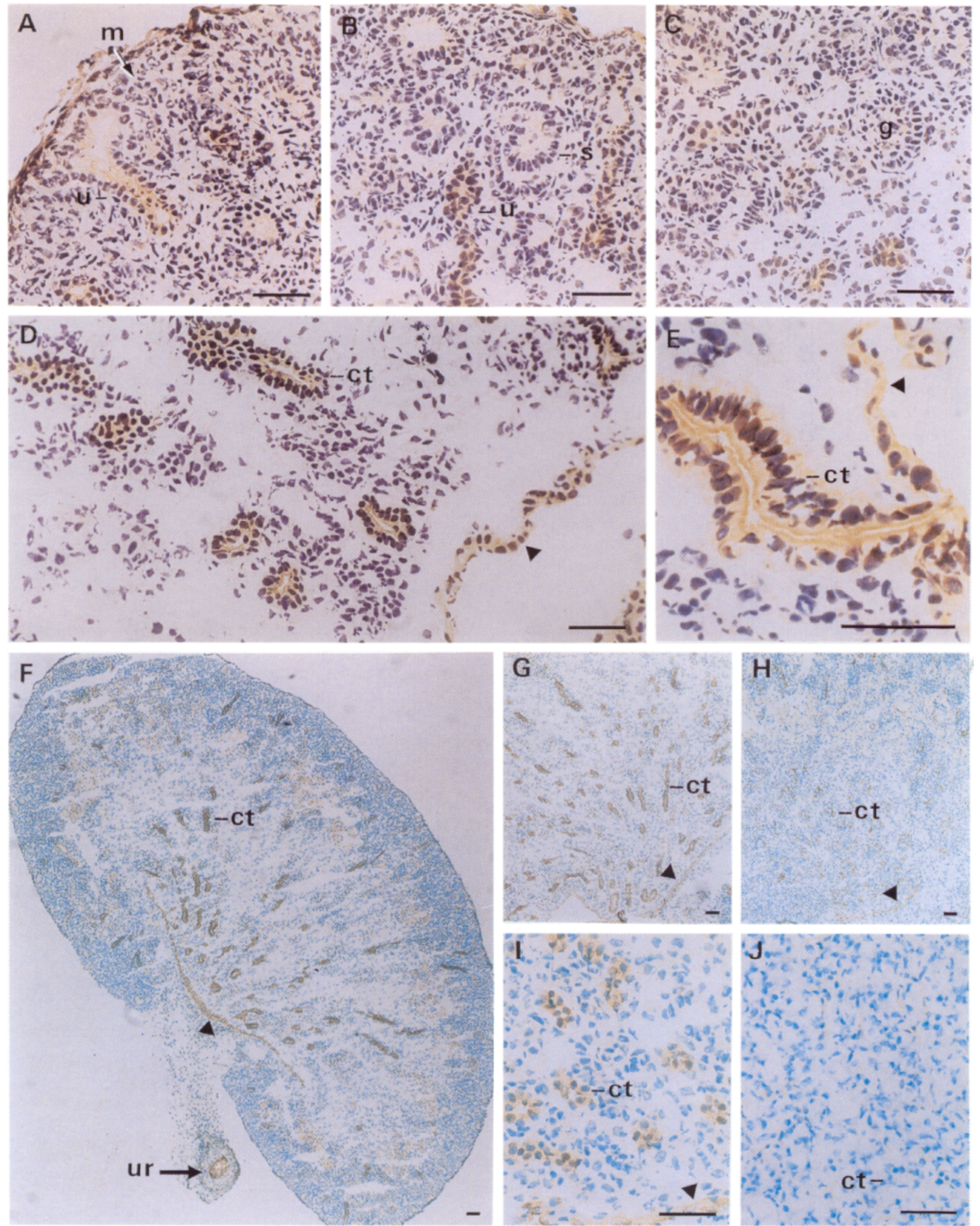

Fig. 7. Immunohistochemistry of polycystin expression in developing and adult kidneys. Rabbit anti-mouse polyclonal antibody mpkcr-Ab with a peroxidase-linked secondary antibody was used to stain $E 15.5(A-E), E 18(F)$, newborn $(G), 1$-wk-old $(H$ and $I)$, and adult $(J)$ kidneys. Polycystin is seen in the ureteric bud $(\mathrm{u})$ and collecting ducts (ct) $(A-J)$. In the collecting duct, staining is more intense near the apical membrane $(D$ and $E)$. High levels of polycystin were detected in the renal papillae $(F-I$; arrowhead) and ureter (ur; $F$, arrow). Polycystin is not present in comma- or S-shaped bodies nor in the developing or mature glomeruli $(\mathrm{g} ; \mathrm{C})$. A developing nephron between the comma- to $\mathrm{S}$-shaped stages is shown $(B)$. In $E 18$, newborn, and postnatal 1-wk-old kidneys, the spatial distribution of polycystin is maintained with no obvious decrease in the level of expression $(F-I)$. In adult kidney $(J)$, however, the tubular staining is hardly detectable. Bar $=66 \mu \mathrm{m}$. 

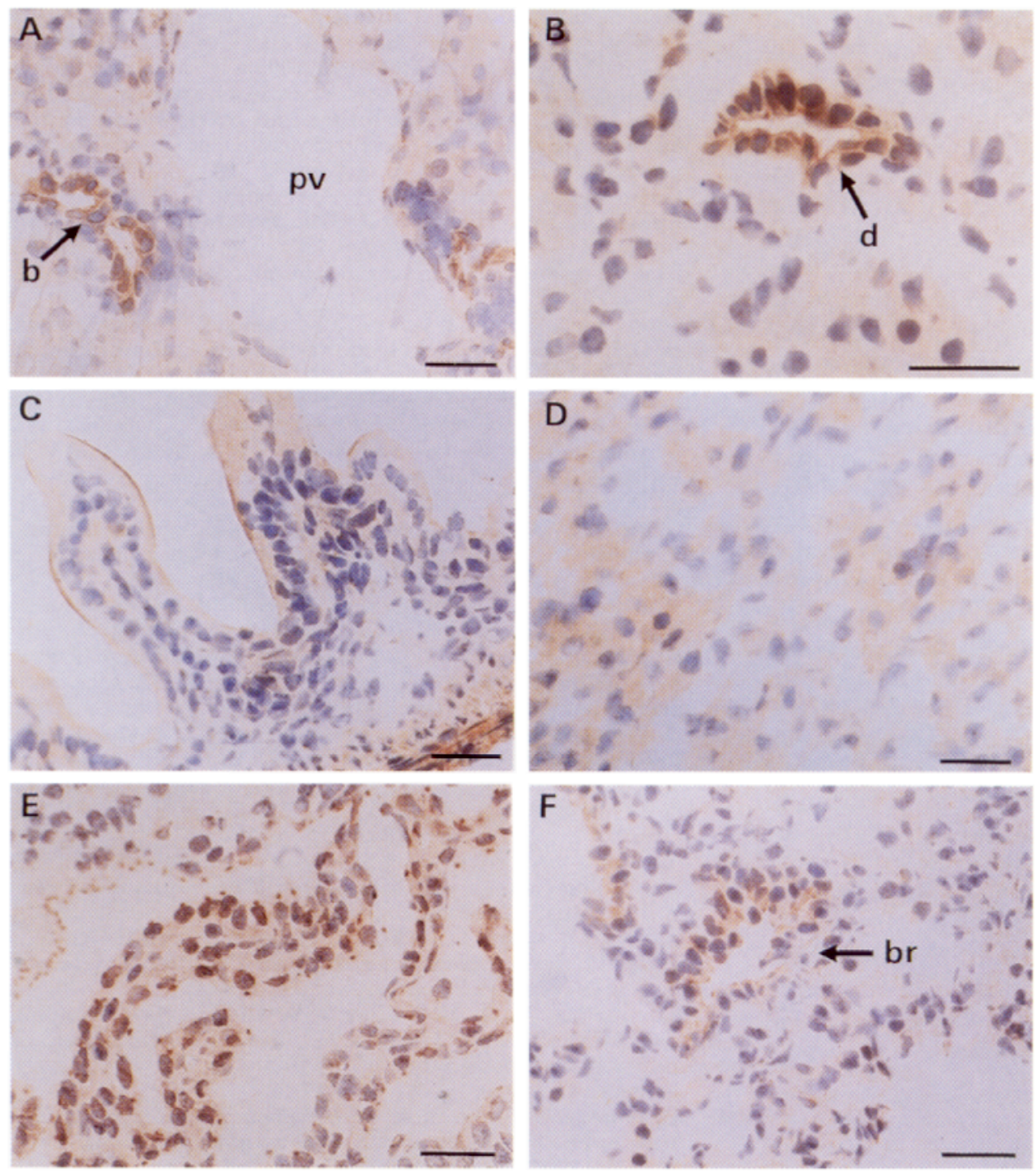

Fig. 8. Immunohistochemistry of polycystin expression in other murine organs. Rabbit anti-mouse polyclonal antibody mpkcr-Ab with a peroxidase-linked secondary antibody was used to stain postnatal day 3 liver $(A)$, pancreas $(B)$, small intestine $(C)$, heart $(D)$, brain $(E)$, and lung $(\boldsymbol{F})$. Polycystin was found in the epithelial cells of hepatic bile ducts (b), pancreatic ducts (d), villi of the intestine, and bronchioles (br). Weak expression could be seen in the hepatocytes, acinar cells, and myocardium but not in the portal vein (pv). Bar $=33 \mu \mathrm{m}$. have therefore isolated a portion of a mouse gene, which we have designated Pkd1, whose deduced peptide sequence has $84 \%$ similarity to human polycystin and which has a transcript of a similar size. An antibody raised to recombinant murine polycystin was used to carry out a survey of its distribution in developing and mature mouse tissues at the transcript and protein levels.

The human and murine proteins were found to have predominant isoforms of $\sim 400 \mathrm{kDa}$. Furthermore, we show that spatial and temporal distribution as well as subcellular localization of polycystin in the murine kidney is in broad agreement with the findings in humans $(9,11,34)$. This study also shows that polycystin is widely expressed in a number of tissues other than the kidney, in agreement with our previous human studies (9). These similarities provide the basis for using the mouse as a model for the study of the physiology and pathophysiology of polycystin.

Our analyses of the levels of the transcript and native protein reveal that murine polycystin has a distinct stage- and cell-specific expression pattern. In the developing kidney, polycystin expression is weakest in the tip of the ureteric bud (Fig. 7A), suggesting that it is unlikely to be required for nephrogenic induction (4). It is, however, strongly expressed in structures derived from the ureter, including straight collecting ducts, papillary ducts, and the renal pelvis. Papillary ducts represent a later developmental stage than straight collecting ducts, since they are formed during the first cycles of branching of the ingrowing ureter (23). Cells from ureter-derived structures divide rather slowly as judged by bromodeoxyuridine immunohistochemistry (22). In fact papillary duct cells cease dividing by E15 (22). A high level of polycystin expression was seen in papillary collecting ducts and the renal pelvis in late kidney development (E18 and newborn), suggesting that polycystin expression does not simply occur, if all other things are equal, with tubule cell proliferation.

Polycystin expression continues in tubular epithelia after birth but, by the third postnatal week, falls to a low level that is maintained into adult life. It is known that anatomic and functional maturity of the collecting ducts is not complete until 21-30 days after birth. For example, microperfusion studies of $\mathrm{Na}^{+}$transport show that maturation of collecting duct occurs in two stages, i.e., a decrease in passive $\mathrm{Na}^{+}$permeability to mature levels by 2 wk due to formation of tight junctions, 
followed by an increase in active $\mathrm{Na}^{+}$transport that begins after $2 \mathrm{wk}$ and approaches adult levels at $3 \mathrm{wk}$ (33). Furthermore, in rodents the characteristic adult pattern of polarization of membrane proteins such as $\mathrm{Na}^{+}-\mathrm{K}^{+}$-adenosinetriphosphatase $\left(\mathrm{Na}^{+}-\mathrm{K}^{+}\right.$-ATPase $)$is not present until several weeks after birth (12).

Polycystin expression is high during differentiation of the collecting ducts and falls dramatically at the time of final maturation of the tubules. It is not clear from these observations, however, whether the change in polycystin levels is primary or secondary. In ADPKD in humans, inherited mutation of polycystin leads to the formation of cysts that are lined by epithelia that have several of the characteristics of immature tubules. Perhaps the best studied manifestation of the immature state is the abnormal polarization of cell surface proteins in ADPKD. For example, $\mathrm{Na}^{+}-\mathrm{K}^{+}$-ATPase is predominantly an apical protein in cysts, whereas it is basolateral in nondilated tubules in ADPKD kidneys and in normal adult kidneys (35). Reversion of epithelia in ADPKD to a state that more closely resembles the developing nephron provides support for the hypothesis $(1,2,15)$ that polycystin plays a role in tubule maturation during development and in maintenance of the mature state during adult life. The concomitant decrease in polycystin levels and tubule maturation in neonatal mouse nephrons provides additional support for this hypothesis.

The availability of antisera to mouse polycystin will allow a range of approaches to an understanding of the function of this molecule. Furthermore, study of the many genetically distinct mouse models of inherited polycystic kidney disease will allow study of the role of polycystin in different types of cystogenesis.

We thank Dr. Harold Chapman for helpful discussion and Drs. Bjorn Olsen and Ramzi S. Cotran for support and encouragement.

This work was supported by National Institute of Diabetes and Digestive and Kidney Diseases Grants DK-51050 (to J. Zhou) and DK-40703 (to S. T. Reeders) and by a grant from the Polycystic Kidney Disease Research Foundation (to J. Zhou). C. Löhning was a recipient of a European Community Fellowship.

Address for reprint requests: J. Zhou, Renal Division, Dept. of Medicine, Brigham and Women's Hospital, Harvard Medical School, 75 Francis St., Boston, MA 02115.

Received 11 October 1996; accepted in final form 25 November 1996.

\section{REFERENCES}

1. Calvet, J. P. Polycystic kidney disease: primary extracellular matrix abnormality or defective cellular differentiation? Kidney Int. 43: 101-108, 1993.

2. Carone, F. A., R. Bacallao, and Y. S. Kanwar. The pathogenesis of polycystic kidney disease. Histol. Histopathol. 10: 213$221,1995$.

3. Daoust, M. C., D. M. Reynolds, D. G. Bichet, and S. Somlo. Evidence for a third genetic locus for autosomal dominant polycystic kidney disease. Genomics 25: 733-736, 1995.

4. Ekblom, P., A. Miettinen, and L. Saxen. Induction of brush border antigens of the proximal tubule in the developing kidney. Dev. Biol. 74: 263-274, 1980.

5. European Polycystic Kidney Disease Consortium. The polycystic kidney disease 1 gene encodes a $14 \mathrm{~kb}$ transcript and lies within a duplicated region on chromosome 16. Cell 77: 881-894, 1994. (published erratum appears in Cell 78: 1994, following $p .724$ )

6. Fossdal, R., M. Bothvarsson, P. Asmundsson, J. Ragnarsson, D. Peters, M. H. Breuning, and O. Jensson. Icelandic families with autosomal dominant polycystic kidney disease: families unlinked to chromosome $16 \mathrm{p} 13.3$ revealed by linkage analysis. Hum. Genet. 91: 609-613, 1993.

7. Gabow, P. A., A. M. Johnson, W. D. Kaehny, W. J. Kimberling, D. C. Lezotte, I. T. Duley, and R. H. Jones. Factors affecting the progression of renal disease in autosomal-dominant polycystic kidney disease. Kidney Int. 41: 1311-1319, 1992.

8. Gattone, V., J. P. Calvet, B. J. Cowley, A. P. Evan, T. S. Shaver, K. Helmstadter, J. J. Grantham, and V. H. Gattone. Autosomal recessive polycystic kidney disease in a murine model. A gross and microscopic description. Lab. Invest. 59: 231-238, 1988 .

9. Geng, L., Y. Segal, B. Peissel, N. Deng, Y. Pei, F. Carone, H. G. Rennke, A. M. Glucksmann-Kuis, M. C. Schneider, M. Ericsson, S. T. Reeders, and J. Zhou. Identification and localization of polycystin, the PKD1 gene product. J. Clin. Invest. 98: 2674-2682, 1996.

10. Grantham, J. J., M. Ye, V. Gattone, L. P. Sullivan, and V. N. Gattone. In vitro fluid secretion by epithelium from polycystic kidneys. J. Clin. Invest. 95: 195-202, 1995.

11. Griffin, M. D., V. E. Torres, J. P. Grande, and R. Kumar Immunolocalization of polycystin in human tissues and cultured cells. Proc. Assoc. Am. Physicians 108: 185-197, 1996.

12. Holthofer, $\mathbf{H}$. Ontogeny of cell type-specific enzyme reactivities in kidney collecting ducts. Pediatr. Res. 22: 504-508, 1987.

13. Hughes, J., C. J. Ward, B. Peral, R. Aspinwall, K. Clark, J. San Millan, V. Gamble, and P. C. Harris. The polycystic kidney disease 1 (PKD1) gene encodes a novel protein with multiple cell recognition domains. Nat. Genet. 10: 151-160, 1995.

14. Iakoubova, O. A., H. Dushkin, and D. R. Beier. Localization of a murine recessive polycystic kidney disease mutation and modifying loci that affect disease severity. Genomics 26: 107-114, 1995.

15. International Polycystic Kidney Disease Consortium. Polycystic kidney discase: the complete structure of the PKD1 gene and its protein. Cell 81: 289-298, 1995.

16. Kanwar, Y. S., and F. A. Carone. Reversible changes of tubular cell and basement membrane in drug-induced renal cystic disease. Kidney Int. 26: 35-43, 1984.

17. Kimberling, W. J., S. Kumar, P. A. Gabow, J. B. Kenyon, C. J. Connolly, and S. Somlo. Autosomal dominant polycystic kidney disease: localization of the second gene to chromosome 4q13-q23. Genomics 18: 467-472, 1993.

18. Martinez, J. R., and J. J. Grantham. Polycystic kidney disease: etiology, pathogenesis, and treatment. Dis. Mon. 41: $693-765,1995$

19. Mochizuki, T., G. Wu, T. Hayashi, S. L. Xenophontos, B. Veldhuisen, J. J. Saris, D. M. Reynolds, Y. Cai, P. A. Gabow, A. Pierides, W. J. Kimberling, M. H. Breuning, C. C. Deltas, D. J. Peters, and S. Somlo. PKD2, a gene for polycystic kidney disease that encodes an integral membrane protein. Science 272 . $1339-1342,1996$

20. Moyer, J. H., T. M. Lee, H. Y. Kwon, J. J. Schrick, E. D. Avner, W. E. Sweeney, V. L. Godfrey, N. L. Cacheiro, J. E. Wilkinson, and R. P. Woychik. Candidate gene associated with a mutation causing recessive polycystic kidney disease in mice. Science 264: 1329-1333, 1994.

21. Mugrauer, G., F. W. Alt, and P. Ekblom. N-myc proto-oncogene expression during organogenesis in the developing mouse as revealed by in situ hybridization. J. Cell Biol. 107: 1325-1335, 1988.

22. Mugrauer, G., and P. Ekblom. Contrasting expression patterns of three members of the myc family of protooncogenes in the developing and adult mouse kidney. J. Cell Biol. 112: 13-25, 1991.

23. Osathanondh, V., and E. L. Potter. Development of human kidney as shown by microdissection. III. Formation and interrelationship of collecting tubules and nephrons. Arch. Pathol. 76: 290-302, 1963.

24. Peissel, B., L. Geng, R. Kalluri, K. Kashtan, H. G. Rennke, G. R. Gallo, M. J. Sun, B. G. Hudson, E. G. Neilson, and J. Zhou. Comparative distribution of the $\alpha 1$ (IV), $\alpha 5$ (IV) and $\alpha 6$ (IV) collagen chains in normal human adult and fetal tissues and in kidneys from X-linked Alport syndrome patients. J. Clin. Invest. 96: 1948-1957, 1995. 
25. Peral, B., V. Gamble, J. San Millan, C. Strong, J. SloaneStanley, F. Moreno, and P. C. Harris. Splicing mutations of the polycystic kidney disease 1 (PKD1) gene induced by intronic deletion. Hum. Mol. Genet. 4: 569-574, 1995.

26. Peral, B., J. San Millan, A. C. Ong, V. Gamble, C. J. Ward, C. Strong, and P. C. Harris. Screening the $3^{\prime}$ region of the polycystic kidney disease 1 (PKD1) gene reveals six novel mutations. Am. J. Hum. Genet. 58: 86-96, 1996.

27. Rauchman, M. I., S. K. Nigam, E. Delpire, and S. R. Gullans. An osmotically tolerant inner medullary collecting duct cell line from an SV40 transgenic mouse. Am. J. Physiol. 265 (Renal Fluid Electrolyte Physiol. 34): F416-F424, 1993.

28. Reeders, S. T., M. H. Breuning, K. E. Davies, R. D. Nicholls, A. P. Jarman, D. R. Higgs, P. L. Pearson, and D. J. Weatherall. A highly polymorphic DNA marker linked to adult polycystic kidney disease on chromosome 16. Nature 317: 542-544, 1985.

29. Schafer, K., N. Gretz, M. Bader, I. Oberbaumer, K. U. Eckardt, W. Kriz, and S. Bachmann. Characterization of the Han: SPRD rat model for hereditary polycystic kidney disease. Kidney Int. 46: 134-152, 1994.

30. Takahashi, H., J. P. Calvet, H. D. Dittemore, K. Yoshida, J. J. Grantham, V. Gattone, and V. H. Gattone. A hereditary model of slowly progressive polycystic kidney disease in the mouse. J. Am. Soc. Nephrol. 1: 980-989, 1991.
31. Trudel, M., V. D'Agati, and F. Costantini. C-myc as an inducer of polycystic kidney disease in transgenic mice. Kidney Int. 39: 665-671, 1991.

32. Turco, A. E., S. Rossetti, E. Bresin, S. Corra, L. Gammaro, G. Maschio, and P. F. Pignatti. A novel nonsense mutation in the PKD1 gene (C3817T) is associated with autosomal dominant polycystic kidney disease (ADPKD) in a large three-generation Italian family. Hum. Mol. Genet. 4: 1331-1335, 1995.

33. Vehaskari, V. M., S. K. Hering, S. Klahr, and L. L. Hamm. Increased sodium transport by cortical collecting tubules from remnant kidneys. Kidney Int. 36: 89-95, 1989.

34. Ward, C. J., H. Turley, A. C. M. Ong, M. Comley, S. Biddolph, R. Chetty, P. R. Ratcliffe, K. Gatter, and P. C. Harris. Polycystin, the polycystin kidney disease 1 protein, is expressed by epithelial cells in fetal, adult, and polycystic kidney. Proc. Natl. Acad. Sci. USA 93: 1524-1528, 1996.

35. Wilson, P. D., A. C. Sherwood, K. Palla, J. Du, R. Watson, and J. T. Norman. Reversed polarity of $\mathrm{Na}^{+}-\mathrm{K}^{+}$-ATPase: mislocation to apical plasma membranes in polycystic kidney disease epithelia. Am. J. Physiol. 260 (Renal Fluid Electrolyte Physiol. 29): F420-F430, 1991.

36. You, G., W. S. Lee, E. J. Barros, Y. Kanai, T. L. Huo, S. Khawaja, R. G. Wells, S. K. Nigam, and M. A. Hediger. Molecular characteristics of $\mathrm{Na}^{+}$-coupled glucose transporters in adult and embryonic rat kidney. J. Biol. Chem. 270: 2936529371, 1995.

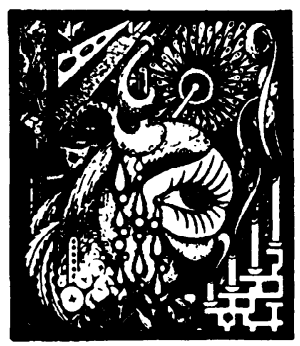

